\section{Prisioneros involuntarios de la arquitectura chilena}

Benjamín Gallegos Gabilondo, Agustina Labarca Gatica

La pasada XIx Bienal de Arquitectura y Urbanismo de Chile titulada «Arquitectura + Educación: el país que queremos» tuvo un gran mérito. Realizada por primera vez fuera de Santiago y con el inédito apoyo de fondos públicos, superó los cinco mil visitantes de las versiones pasadas, contando con más de treinta mil asistentes.

Asimismo, se introdujeron diversas modificaciones en su estructura. El Colegio de Arquitectos, aún presidido por Sebastián Gray, incorporó en el comité organizador a la Asociación de Oficinas de Arquitectos y la Red de Escuelas de Arquitectura. Al mismo tiempo, el equipo curatorial fue seleccionado mediante un concurso público, quedando conformado por Fernando Marín, Francisca Pulido, Gabriela de la Piedra y el Grupo Arquitectura Caliente.

El montaje se presentó dividido en dos grandes secciones: la muestra profesional y la muestra académica. La primera se organizó como un gran recorrido por Chile a través de I27 obras de las cuales se destacaban 36 proyectos representativos del estado de la arquitectura a nivel nacional. Las obras estaban expuestas en una superficie desplegada y densa de información, articulándose a lo largo de todo el territorio chileno. Región tras región, sin embargo, se hacía evidente la decisión de los curadores. En vez del país que queremos, como muchos visitantes esperaban, se trataba de una fotografía del país que tenemos o, para ser más precisos, de la arquitectura que se produce en el territorio en el que estamos. Sin proponer un punto de vista nuevo, la selección se limitó a las obras enviadas por los arquitectos colegiados de cada región.

Por otra parte, la muestra académica contó con la participación de más de 20 escuelas. Contrario a la colaboración que se esperaría, las distintas instituciones dedicadas a enseñar y pensar la arquitectura, plantearon su propia muestra en términos de oferta. En los paneles a cargo de las distintas universidades no se hilvanaba un discurso, por lo que las comparaciones que podían hacerse eran más bien banales, dando la sensación de que las propuestas académicas fueron reemplazadas por stands publicitarios. Más aún, los estudiantes, inducidos por una evidente pretensión profesional, presentaron proyectos que renunciaban a la oportunidad de ser una contraparte interesante en el debate.

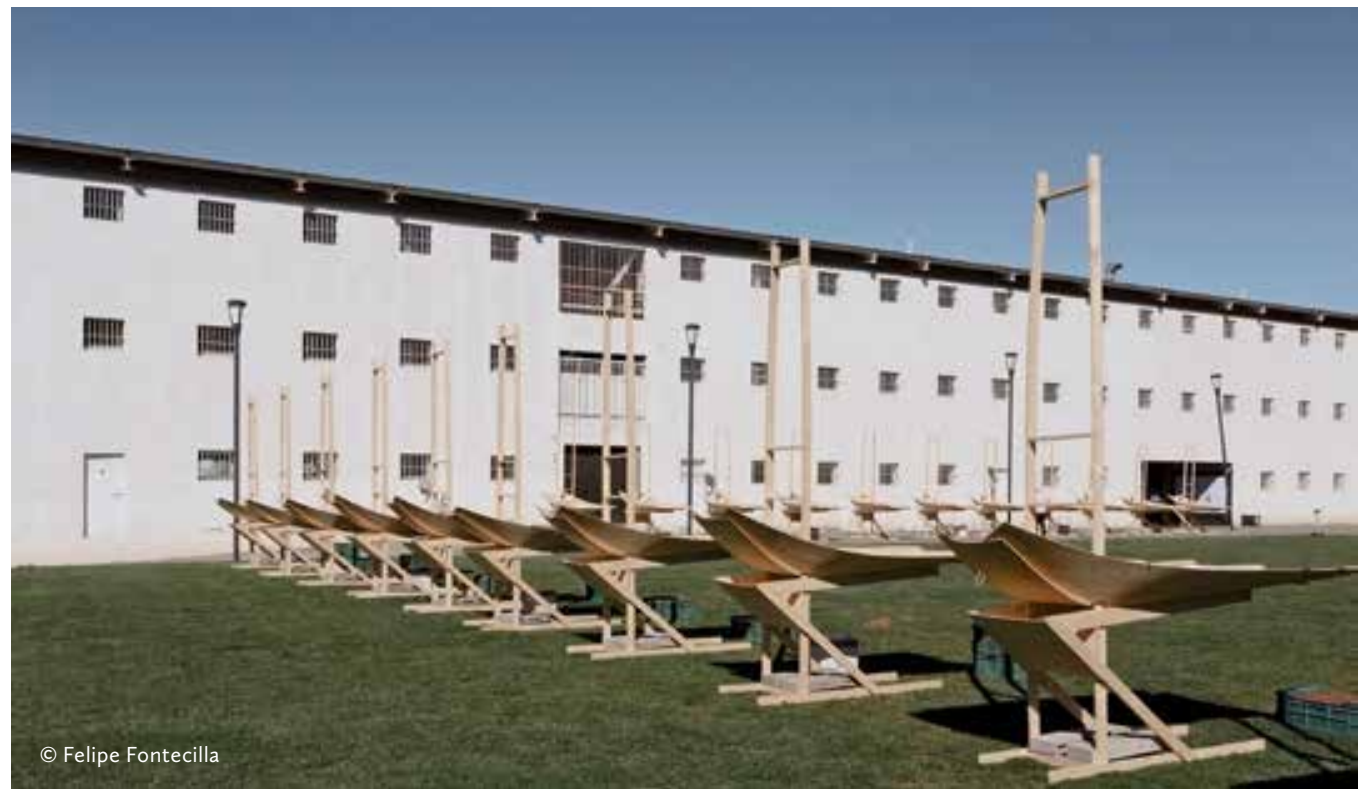

Ambas secciones de la muestra dejaron en evidencia el estado de las cosas. Si bien los curadores manifestaron esta intención en sus discursos, hubo una directa contradicción con el título de la bienal -el país que queremos-. Evidentemente no bastó con convocar a distintos actores, incluir todo el territorio nacional o concursar las distintas partes de la muestra. Los intentos de democratización pueden resultar infructuosos si la disciplina sigue siendo autocomplaciente. La arquitectura chilena ya está posicionada en relación a ciertos valores, ha sido extensamente publicada y cuenta con profesionales de reconocida trayectoria. Seguir festejando la realidad arquitectónica que tenemos y el sistema académico que la produce equivale a un encierro.

No obstante, la exposición tuvo un prófugo.

Un grupo de escuelas de arquitectura decidió realizar un montaje en el barrio puerto. El contraste se evidenciaba aún más, ya que se encontraba en el palacio Subercaseaux, uno de los edificios abandonados de la zona. El acierto del proyecto estuvo en la simpleza con la cual dialogaba y completaba la ruina del edificio existente (ver págs. 86-9I), transformándola en la señal de que algo estaba ocurriendo en su interior. Esto, a pesar de que los proyectos presentados y el plan maestro para la zona portuaria de Valparaíso resultaban ingenuos y poco significativos respecto a la apuesta que se proponía. Sin embargo, este gesto amplió los juicios que podían hacerse sobre la estructura de la exhibición, indicando un camino positivo respecto al potencial de esta institución y lo que se puede lograr con la colaboración entre academias.

En este sentido, las bienales no están llamadas sólo a presentar obras ni son plataformas donde todos pueden subir contenidos, sino que debieran poner en discusión y permitir la crítica sobre el estado de la disciplina. Las nubes de conceptos y el uso repetitivo de hashtags reforzaban la sensación de estar ante una página web; esta confusión entre las formas y los contenidos dejó en evidencia una inquietante incapacidad para enfrentar los temas de la arquitectura contemporánea.

Las treinta mil personas que asistieron al evento se encontraron frente a demasiados proyectos y pocas ideas nuevas. Estando ahí era muy alentador ver la cantidad de estudiantes y el gran entusiasmo con que se tomaban las actividades propuestas. Esto es sintomático de lo necesaria que es la bienal como institución en el debate arquitectónico. Sin embargo, la muestra no fue capaz de responder al interés que ella misma despertó, atrapando involuntariamente a los visitantes en una cárcel.

Esta cárcel de autocelebración puede ser particularmente peligrosa. Habernos convertido en prisioneros involuntarios significa haber perdido la distancia necesaria para juzgar los valores que se le reconocen a la arquitectura chilena. La bienal debería tener el coraje para salir de este encierro. Por el contrario, en su XIX edición reforzó estos límites y bajo la promesa del país que queremos se limitó a mostrar el estado de las cosas, señalando la urgencia de una mirada crítica sobre la arquitectura que tenemos. ARQ

\section{BENJAMÍN GALLEGOS GABILONDO}

Arquitecto, Instituto Universitario di Architettura di Venezia (IUAV), 20I4. También realizó estudios de pregrado en la Universidad de Strathclyde, Glasgow, en el 2012. Es coeditor de The Ship, proyecto editorial que diseñó la exposición Archizines en Venecia en 2013 y que colaboró en el proyecto Ground Floor Crisis para Monditalia en 2014 durante la xıv Bienal de Venecia.

\section{AGUSTINA LABARCA GATICA}

Estudiante de Magíster de Arquitectura, Pontificia Universidad Católica de Chile. En el 2012 realizó estudios en el Instituto Universitario di Architettura di Venezia (IUAV). 